\title{
DIE HERONTDEKKING VAN DIE KLASSIEKE LETTERKUNDE
}

\section{GEDURENDE DIE RENAISSANCE}

\section{W.J. Henderson, Randse Afrikaanse Universiteit}

Die oorlewingsgeskiedenis van Griekse en Latynse tekste is een van enorme verliese en wonderbaarlike reddingsdade oor twee-en-'n-half duisend jaar. Geen of swak skryfmateriaal, geen of gebrekkige biblioteke, oorloë, brand, verrotting, verwaarlosing en diefstal het almal 'n aandeel gehad in die verlies van die grootste gedeelte van die Grieke en Romeine se letterkundige produksie. Geleerdes en nie-so-geleerdes, aristokrate, regeerders, monnike en pouse het weer met die nodige kennis, entoesiasme, toewyding en belangstelling heelwat gered wat andersins verlore sou gegaan het. Gewilde outeurs, wie se werke ten spyte van hulle nie-Christelike inhoud en gees in die opvoedkundige program aanvaarbaar was, was seker nooit in gevaar nie. Maar meer as een Klassieke werk het tot die uitvinding van die boekdrukpers op grond van net een manuskrip oorleef wat dan daarna verlore gegaan het (Reynolds-Wilson 1968:86, 116; Sweeney 1971:35).

Die Renaissance het nie sommer spontaan ontstaan nie: daar was ten minste van die vorige eeu voorgangers (Reynolds-Wilson 1968:93-96; Billanovich 1971:57-66; Jeauneau 1971:95-102). Die humaniste het ook reeds 'n erfenis van tekste en geakkumuleerde kommentaar op die tekste tot hulle beskikking gehad. Trouens, die meerderheid van die Griekse en Latynse werke wat vandag nog bestaan, dateer eintlik uit die Middeleeue, d.w.s. die vier eeue voor die Renaissance (Reynolds-Wilson 1968:69-72, 83-86, 94-95 98-99). In hierdie artikel val die fokus op die rol van die vroeë Italiaanse humaniste in die herontdekking van die Klassieke letterkunde en die onmiddellike gevolge daarvan vanaf die begin van die 14de eeu tot die verskyning in druk van die eerste Klassieke werke vanaf 1465.

Die "humanisme" wat aan die Renaissance sy dryfkrag gegee het, was hoofsaaklik 'n litereare aktiwiteit wat met die bestudering en nabootsing van die styl en inhoud van die Klassieke letterkunde verbind was. Die woord umanista het immers gedui op 'n dosent van die sogenaamde studia humanitatis, nl, die grammatika, retoriek, geskiedenis, poësie en morele filosofie, waarvan die basiese studiemateriaal die Klassieke werke was (Reynolds-Wilson 1968:101; kyk ook Pfeiffer 1976:15-17).

Die eerste prestasie van die humaniste was die versameling van reeds bekende manuskripte en die ontdekking van werke wat teen hulle tyd onbekend of verwaarloos was. Die reeks rampe wat die Griekse en Romeinse wêrelde getref het, die vernietiging van die Mouseion- en Serapeion-biblioteke in Alexandrië in 272 en 391 n.C., die barbaarse invalle in die Romeinse Ryk vanaf die 5de eeu n.C., die vernietiging van Konstantinopel deur die Frankiese Vierde Kruistog in 1206, en die finale val van Konstantinopel in 1453 het Griekse en Latynse boeke heen-en-weer tussen Ooste en Weste, maar ook na Europa laat versprei, waar hulle in die klooster- en katedraalbiblioteke bewaar en gekopieer is. Vir die eerste tweehonderd jaar van die Renaissance in Italië, vanaf ongeveer die dood van Dante in 1321 tot die dood van Pous Leo X in 1521 (Sandys 1908:1,3), is groot hoeveelhede van hierdie manuskripte van Europa en die Ooste versamel en terug na Italië gebring. Konings soos Alfonso $\mathrm{V}$ van Napels, prinse soos Hertog Federico van Urbino, pouse soos Nikolas V, en aristokratiese families soos die Medici van Florence het groot biblioteke gestig of ondersteun (Pfeiffer 1976:49-50).

Die grootste literêre figuur van die Renaissance, Francesco Petrarca (1304-1374), het 'n ingrypende rol in die oorlewingsgeskiedenis van 'n menigte manuskripte gespeel (Sandys 1908:3-11; Reynolds-Wilson 1968:105-111). As balling in Avignon, wat die pouslike setel vanaf 1309 tot 1377 was, het hy die kans benut om die manuskripskatte van die klooster- en 
katedraalbiblioteke van Frankryk en Duitsland te ontgin. Onder sy ontdekkings was 'n toespraak en twee versamelings briewe van Cicero (Pro Archia, in Lìge, 1333; Epistulae ad Atticum en Epistulae ad Quintum Fratrem en ad Brutum, in Verona, 1345). Teen 1329 besit hy die volledigste en betroubaarste teks van Livius in sy tyd. Daarbenewens het hy kopieë van die meeste van die Latynse werke wat in sy dag nog in omgang was, versamel. Van sy rol skryf Rudolf Pfeiffer (1976:12): "In the end nearly all the classical Latin texts known in his time had been collected, read, and more or less fully annotated in their margins by Petrarch himself; he was the first man of letters in modern times to build up a private library of this kind".

Sy dissipel Giovanni Boccaccio (1313-1375) herontdek op sy beurt verlore of verwaarloosde werke van outeurs soos Varro (De lingua Latina), Martialis, Ausonius, Ovidius (Ibis), die Appendix Vergiliana, Fulgentius, Lactantius Placidus, die Priapeia en dalk ook Tacitus se Historiae en die laaste gedeelte van die Annales (Sandys 1908:11-16, 32-33; Pfeiffer 1976:2324).

In hierdie konteks kan ook Coluccio Salutati (1331-1406) uitgesonder word. Hy was 'n swak digter en geleerde, maar het as Kanselier van Florence vir dertig jaar sy posisie van gesag gebruik om die humanisme te bevorder. Hy het manuskripte versamel en vergelyk, korrupsies in die tekste nagespeur, Griekse studies gestimuleer, en 'n eie biblioteek van meer as agt honderd manuskripte opgebou, waarvan 111 steeds bestaan. Hy het ' $n$ afskrif van die codex Veronensis van Catullus, asook die eerste eksemplare van o.a. Cato se De agricultura en Germanicus se Aratea besit. Hy was die eerste om die volledige versameling van Cicero se briewe na eeue weer bymekaar te he (Sandys 1908:17-19; Reynolds-Wilson 1968:111-113; Pfeiffer 1976:25-27).

Die grootste ontdekker van ou manuskripte was egter Poggio Bracciolini (1380-1459), pouslike sekretaris, skrywer en polemikus. Sy posisie aan die pouslike hof by die Konsilie van Konstanz (1414-1418) stel hom in staat om vier reise na verskeie kloosters in die omgewing (o.a. Cluny, St Gallen, Langres, Fulda en dalk Reichenau) te onderneem. So het hy etlike belangrike manuskripte in die hande gekry en gekopieer of laat kopieer: Cicero se toesprake, Quintilianus se Institutio oratoria, dele van Valerius Flaccus se Argonautica, Lucretius se De rerum natura, Silius Italicus se Punica, dele van Ammianus Marcellinus se geskiedenis, Statius se Silvae, en Petronius se Cena Trimalchionis (Sandys 1908:25-32; Reynolds-Wilson 1968:113-116; Pfeiffer 1976:31-34). Poggio was ook indirek betrokke, deur die bemiddeling van vriende, vir die ontdekking van bv. Cicero se De oratore, Orator en Brutus, Tacitus se Agricola, Germania en Dialogus, twaalf nuwe komedies van Plautus, en Frontinus se werk oor die akwadukte (Sandys 1908:31-34; Reynolds-Wilson 1968:115-116).

Die meeste van die Latynse letterkunde wat vandag aan ons bekend is, is reeds teen die 16de eeu deur hierdie entoesiaste teruggevind, gekopieer en aan ander beskikbaar gestel (ReynoldsWilson 1968:115). Die humaniste het in allerlei werke uit die oudheid belang gestel, en nie net die werke wat relevant of aanvaarbaar was in die oë van die Kerk wat deur middel van die klooster- en katedraalskole vir so lank die monopolie op die opvoeding gehad het nie. In hierdie proses is die Kerk se monopolie op die gebruik van Latyn gebreek: die meer sekulêre letterkunde kry ook nou aandag.

Wat die versameling van Griekse boeke betref, presteer veral Kardinaal Bessarion (c.14001472), 'n Griekse monnik wat in 1438 na Italië vir die Konsilie van Florence en Ferrara gekom en in Italië gebly het. Sy groot versameling van Griekse boeke het mettertyd die kern van die huidige biblioteek van Venesië geword (Sandys 1908:61; Reynolds-Wilson 1968:124128). Guarino da Verona (1374-1460) het in 1408 van Konstantinopel na Venesië met vyftig Griekse manuskripte teruggekeer (Sandys 1908:49); in 1423 het Giovanni Aurispa 238 Griekse boeke na Italië teruggebring (Sandys 1908:36-37; Reynolds-Wilson 1968:124; Pfeiffer 1976:48); en Francesco Filelfo (1398-1481), Venesiaanse attaché in Konstantinopel 
van 1420 tot 1427, het veertig manuskripte teruggebring (Sandys 1908:37; Reynolds-Wilson 1968:124; Pfeiffer 1976:48). In 1491 het Janus Lascaris (1445-1535), agent van Lorenzo de' Medici, twee honderd Griekse manuskripte van Berg-Athos na Florence gebring (Sandys 1908:37, 78; Pfeiffer 1976:47-49).

Die versameling van manuskripte, die onderlinge vergelyking daarvan, die onderskeiding tussen egtes en valses, en die opteken van variante lesings het die tekskritiek bevorder. Skeptisisme is al uitgespreek oor die werklike tekskritiese aktiwiteite en prestasies van die humaniste en daarmee hulle rol in die ontwikkeling van die Klassieke filologie (Wilamowitz 1982:20-39; Kenney 1971:119-128). Die prestasies van die humaniste moet egter nie net in terme van hulle bydrae tot die Klassieke filologie gesien word nie. In die geskiedenis van die tekskritiek is die bydrae van Lorenzo Valla (1407-1457) en Angelo Poliziano (1454-1494) nie te negeer nie.

Eersgenoemde het Grieks en Latyn geken, en het as pouslike sekretaris toegang tot die Vatikaan-biblioteek gehad. Vanaf 1450 beklee hy die leerstoel in retoriek in Rome. In 1440 bewys hy op grond van die Latyn en vergelyking met ouer manuskripte dat die Donatio Constantini, wat aan die pous groot dele van Italië "bemaak" het, 'n vervalsing was. Hy bewys ook die valsheid van die sogenaamde "korrespondensie" tussen Seneca en Paulus. In 1446/47 verskyn sy korreksies van ses boeke van Livius, die Emendationes sex librorum Titi Livi, en in 1449 sy emendasies en notas oor die Vulgata, waarin hy 'n vergelyking tref tussen die Latynse vertaling van Hieronymus en die Griekse en Patristiese tekste, en wat in 1505 deur Erasmus uitgegee is (Reynolds-Wilson 1968:118-119; Pfeiffer 1976:35-41).

Angelo Ambrogini, meer bekend onder sy bynaam Poliziano, was die leermeester van Lorenzo de' Medici se kinders en op dertigjarige leeftyd professor in Griekse en Latynse letterkunde. Hy konsentreer op die interpretasie van veral die Latynse poësie deur middel o.a. van 'n studie van die Grieks-Romeinse kultuurwêreld, maar bestudeer ook die Romeinse reg. Hy gee lesings oor Homeros, Hesiodos, Theokritos, Kallimachos en die Griekse Antologie, met inleidings in vers. Hy word so die eerste Italianer wat belangrike werk verrig op die Griekse taal- en letterkunde. In 1489 publiseer hy sy Miscellanea, aantekeninge oor en besprekings van taalkundige, tekskritiese, chronologiese en antikwariese vraagstukke, en herkonstruksies van verlore Griekse tekste vanaf aanhalings en Latynse nabootsings (Sandys 1908:83-86; Reynolds-Wilson 1968:119-121,128-129; Pfeiffer 1976:42-46).

Bewondering vir die skoonheid van vorm en klank van die Latynse taal het die kennis van Latyn bevorder. Grammatikaboeke en woordelyste het verskyn wat die kennis van Latyn, voorheen die monopolie van die Kerk, gedemokratiseer het. Guarino van Verona publiseer in 1418 sy Regulae grammaticae, en Lorenzo Valla skryf in 1440 die Elegantiae Latini sermonis, 'n werk oor Latynse styl, taalgebruik en grammatika, wat in 1471 gedruk is, en teen 1536 reeds nege-en-vyftig uitgawes beleef het (Sandys 1908:68-69; Reynolds-Wilson 1968:118; Pfeiffer 1976:35). In 1468 verskyn Niccolo Perotti se Rudimenta grammatica, wat in 1473 gedruk is en deur Erasmus as die volledigste Latynse grammatika van sy tyd beskou is (Sandys 1908:71).

Ook die Griekse taal en letterkunde het die aandag van die humaniste geniet. Hulle het Grieks geleer, Griekse grammatikas geskryf en Griekse werke in Latyn vertaal om ' $n$ breër gehoor te bereik, wat nie meer albei Klassieke tale magtig was nie. Boccaccio word beskou as die eerste moderne mens in die Weste om Grieks te leer, alhoewel die inhoud eerder as die taal van die Griekse werke in sy besit hom geïnteresseer het. Hy het in 1360 Leonzio Pilato na Florence genooi om Grieks te doseer (Sandys 1908:15-16). Salutati het in 1396 die Griekse geleerde, Manuel Chrusoloras (c.1350-1415), na Florence gebring waar hy vanaf 1397 tot 1400 Grieks gedoseer het. Sy Griekse grammatika, Erôtêmata tès Hellênikês glôssês, het in 1471 die eerste gedrukte Griekse grammatika word (Reynolds-Wilson 1968:123). Constantinus Lascaris 
publiseer sy Griekse grammatika in 1476; in 1508 druk die Aldus-pers dit, en in 1966 word dit herdruk (Pfeiffer 1976:53).

Omdat die kennis van Grieks beperk was, was 'n vertaling vir die meeste Italianers buite die intellektuele kringe van die groot humaniste die enigste toegang tot die Grieks-Romeinse verlede. Die vertaling van Griekse werke was dus een van die belangrikste aktiwiteite van die humaniste. Chrusoloras en sy leerling, Leonardo Bruni (c.1370-1444), wat Kanselier van Florence geword het, het etlike Griekse werke in Latyn vertaal (Sandys 1908:19, 45-47, 61; Pfeiffer 1976:27). Gedurende die volgende sestig jaar word die belangrikste Griekse tekste in Latyn of Italiaans vertaal (Sandys 1908:45-90). Die invloed van hierdie vertalings was enorm: die skeppende kunstenaars is sowel deur die groot letterkundige werke as die nie-literere of tegniese geskrifte van die Grieke en Romeine geïnspireer. Columbus van Genoa se vaart weswaarts om Indië te bereik was gebaseer op die gedagte van ' $n$ aarde wat rond is, juis die teorie van die Alexandrynse geleerde, Claudius Ptolemaeus (floruit 127-148 n.C.); en Leonardo da Vinci kon die Automata van Heron van Alexandrië (2de eeu n.C.) vir sy modelle en uitvindsels gebruik (Wilamowitz 1982:24).

Werk aan die manuskripte het belangstelling in die kultuurwêreld waaruit hulle ontstaan het, gestimuleer. Hulpdissiplines soos geskiedenis, argeologie, epigrafie en numismatiek het begin ontwikkel. Daar is ' $n$ nuwe belangstelling in die sosio-politieke instellinge, godsdiens en militêre gebruike van die Romeine. Die "Altertumswissenschaft" van die 19de eeu is so geantisipeer. Petrarca skryf sy De viris illustribus, biografieë van beroemde Romeine van Romulus na Traianus (Pfeiffer 1976:7). Groot ensiklopedieë oor antieke biografie, geskiedenis, geografie en mitologie, soos dié van Boccaccio, verskyn. Sy Genealogie deorum gentilium met mitologiese, historiese en geografiese stof, word die handboek vir Renaissance digters en skilders tot 1550 (Pfeiffer 1976:20-21). Daarby het hy twee biografiese versamelings (De mulieribus claris en De casis virorum illustrium) en ' $n$ werk oor die name van berge, woude en fonteine (De montium, sylvarum, fontium nominibus) saamgestel (Pfeiffer 1976:20-22).

Op die gebied van die versameling van argeologiese oorblyfsels, insluitend inskripsies, was Ciriaco de' Pizzicolli (c.1391-c.1450) besonder aktief 'n goeie vier honderd jaar voor die begin van wetenskaplike opgrawings (Sandys 1908:39-40; Pfeiffer 1976:51). Flavio Biondo (1392-1463) bestudeer die fisiese oorblyfsels van die Romeinse beskawing, en publiseer sy Roma triumphans (1456-1460), Roma instaurata (1440-1463) en Italia illustrata (1456-1460). Sy Historiarum ab inclinatione Romanorum decades is die eerste poging om die opkoms en val van die Romeinse Ryk te behandel (Sandys 1908:40-41; Pfeiffer 1976:50-51).

Studie en kennis van veral die Latynse letterkunde het die skryf van eie werke in vers of prosa waarin die Klassieke ideale, styl en idees vergestalt was, gestimuleer. Baie van die humaniste was geleerdes en skeppende skrywers, in Latyn én Italiaans. Hulle het dikwels ereplekke ingeneem in die geskiedenis van die Italiaanse letterkunde. Petrarca, groot digter in eie reg, word ' $n$ leidende figuur in die wetenskaplike studie van die antieke skrywers én in sy ideaal om hulle na te streef en selfs te oortref (Reynolds-Wilson 1968:105-106; Pfeiffer 1976:3-20). Daar is reeds verwys na werke wat aan die begin staan van die ontwikkelende wetenskappe soos die tekskritiek, die Klassieke taalkunde en die "Altertumswissenschaft". Baanbrekerswerk is egter ook gedoen op die inheemse geskiedenis (Bruni, Historiarum Florentini populi libri, in 12 volumes, 1404-1444; Pfeiffer 1976:30; en Poggio, Historia Florentina, 'n voortsetting daarvan; Pfeiffer 1976:33); teologie en filosofie (Nicolai de Cusa, De concordantia catholica, 1433; Pfeiffer 1976:39; Valla, De voluptate, 1431-1433, Dialecticae disputationes contra Aristotelicos, 1433-1438, De libero arbitrio, en De professione religiosorum, c.1442; Pfeiffer 1976:40).

Vir die oordrag van die kennisontploffing het nuwe skole of akademies gegroei. In Florence was daar die Studio (gestig in 1321; Pfeiffer 1976:56) en die Platoniese Akademie (gestig 
deur Giorgios Gemistos in 1439; Sandys 1908:60-61; Pfeiffer 1976:57-58), in Rome die Akademie van Pomponio Leto (1428-1497) (gestig in 1460; Sandys 1908:92-93; Pfeiffer 1976:51-52, 56), en in Venesië die Sodalitas Philellênôn (gestig in 1500; Pfeiffer 1976:56). Geleidelik het die sekulêre opvoedkundige inrigtings van die humaniste die klooster- en katedraalskole vervang.

Die liefde vir mooi vorm het die behoefte geskep na 'n mooi skriftipe. Die pragtige Karolingiese minuskel het voortgeleef as basis vir die humanistiese skrif (Pfeiffer 1976:13). Die nuwe belangstelling in boeke stimuleer die boekhandel, wat dan weer spoedig uitloop op die uitvinding van die boekdrukpers. Twee Duitsers, Sweinheim en Pannartz, het van Maintz na Rome gekom, en die eerste uitgawes van verskeie Latynse werke van 1465 tot 1471 gedruk. Teen 1500 is ongeveer vyf duisend werke in Italië gedruk, waarvan meer as die helfte in Venesië gedoen is. Dit is juis ook in Venesië waar Aldus Manutius (1449-1515) en sy assistent Marcus Musurus (1470-1517) verantwoordelik was vir die eerste uitgawes van byna al die belangrike Griekse outeurs (Sandys 1908:79-80; 95-105; Reynolds-Wilson 1968:129133). Die Aldus-pers druk sewe-en-twintig editiones principes van Griekse werke in een-entwintig jaar. Aldus was ook verantwoordelik vir die instelling van die hedendaagse kursief wat vanaf 1501 vir kleiner uitgawes van die Latynse en Italiaanse outeurs gebruik is. Teen 1550 was die meeste oorlewende Klassieke tekste in boekvorm gedruk (Kenney 1971:127).

Verskeie ontwikkelinge het hulle oplewing of herlewing gedurende die Renaissance gehad: o.a. openbare biblioteke, die tydgenootlike letterkunde en kuns, die humanistiese universiteite, die.moderne wetenskap. In al hierdie prosesse, wat die neerslag van die "revival of learning" was, was die rol van die herontdekking van die Griekse en Latynse boek beslissend.

\section{BIBLIOGRAFIE}

Billanovich, G. 1971. "I primi umanisti e l'antichità classica", in Bolgar (red.) 1971:57-66.

Bolgar, R.R. (red.) 1971. Classical Influences on European Culture A.D. 500-1500. Cambridge: University Press.

D'Alverny, M.-Th. \& Garand, M.-C., 1971. "L'Institut de recherche et d'histoire des textes et l'étude des manuscrits des auteurs classiques", in Bolgar (red.) 1971:37-42.

Jeauneau, E. 1971. "La lecture des auteurs classiques à l'école de Chartres durant la première moitié du XIle siècle", in Bolgar (red.) 1971:95-102.

Kenney, E.J. 1971. "The character of humanist philology", in Bolgar (red.) 1971:119-128.

Pfeiffer, R. 1976. History of Classical Scholarship from I300 to 1850. Oxford: Clarendon Press.

Reynolds, L.D. \& Wilson, N.G. 1968. Scribes and Scholars. A Guide to the Transmission of Greek \& Latin Literature. Oxford: University Press.

Sandys, J.E. 1908. A History of Classical Scholarship, vol.2. Cambridge: University Press.

Sweeney, R.D. 1971. "Vanishing and unavailable evidence: Latin manuscripts in the Middle Ages and today", in Bolgar (red.) 1971:29-36.

Wilamowitz-Moellendorff, U. von. 1982. History of Classical Scholarship. Vertaal uit die Duitse uitgawe van 1927 deur A. Harris, met 'n Inleiding deur H. Lloyd-Jones. London: Duckworth. 